\title{
BMJ open Adverse events related to intravenous antibiotic therapy: a prospective observational study in the treatment of infective endocarditis
}

To cite: De Paula DHG, Tura BR, Lamas C da C. Adverse events related to intravenous antibiotic therapy: a prospective observational study in the treatment of infective endocarditis. BMJ Open 2012;2: 001189. doi:10.1136/bmjopen-2012001189

- Prepublication history and additional material for this paper are available online. To view these files please visit the journal online (http://dx.doi.org/10.1136/ bmjopen-2012-001189)

Received 4 April 2012 Accepted 4 September 2012

This final article is available for use under the terms of the Creative Commons Attribution Non-Commercial 2.0 Licence; see http://bmjopen.bmj.com

${ }^{1}$ Department of Surgery, Instituto Nacional de Cardiologia, Rio de Janeiro, Brazil

${ }^{2}$ Department of Biostatistics and Bioinformatics, Instituto Nacional de Cardiologia, Rio de Janeiro, Brazil

${ }^{3}$ Professor of Infectious Diseases, Unigranrio, Rio de Janeiro, Infection Control Committee, Instituto Nacional de Cardiologia, Rio de Janeiro, Brazil

\section{Correspondence to} Dr Débora Holanda Gonçalves De Paula; dhgpaula@gmail.com

\section{ABSTRACT}

Objective: The goal of this prospective observational study was to identify adverse events (AEs) related to the use of intravenous access sites used for infective endocarditis (IE) treatment in a tertiary care hospital.

Design: This is an observational, analytical and prospective study on AEs resulting from the use of intravenous access sites in patients under antimicrobial treatment for IE. Patients enrolled in the International Collaboration on Endocarditis (ICE) study had their peripheral, short-term central catheters (CVC) and peripherally inserted central catheters (PICC) monitored for AEs.

Setting: Tertiary care hospital for cardiac surgery in Rio de Janeiro, Brazil.

Patients: Patients over 14 years of age, hospitalised in 2009 and 2010 with possible or definite criteria for IE by the modified Duke criteria were included.

Main outcome measures: AEs related to intravenous catheters: erythema and infiltration, fever, obstruction, externalisation and blood stream infection.

Results: Thirty-seven episodes of IE in 35 patients were studied. Mean patient age was $44.32 \pm 15.2$ years; 22 $(63 \%)$ were men. The number of vascular catheters studied were 253, 148 of which were peripheral, 85 CVC (21 of which for haemodialysis) and 20 PICC. The most frequent AEs were 'erythema' and 'infiltration' for peripheral catheters, 'fever' for CVCs and 'obstruction' and 'externalisation' for PICCs. The number of catheterdays was 360 for peripheral catheters, 1.156 for CVC and 420 for PICC. Kaplan-Meier curves for CVC and PICC showed statistical difference for obstruction $(p<0.001)$ in PICCs. More bacteraemia occurred in CVC compared with PICC.

Conclusions: The choice of intravenous access sites is critical in the treatment of IE. Close observation for AES and stricter implementation of infection control measures and better manipulation of catheters are suggested.

\section{INTRODUCTION}

The rate of adverse events (AE) is an important marker of patient safety. AE may be

\section{ARTICLE SUMMARY}

Article focus

- To study the adverse events (AE) related to intravenous antibiotic treatment in infective endocarditis (IE), analysing infective and mechanical problems regarding peripheral catheters, shortterm central venous catheters (CVC) and peripherally inserted central catheters (PICC).

Key messages

- The choice of intravenous access sites is critical in the treatment of IE and should be done early on admission.

- Short-term CVC have the important AE of associated line infection, with bacteraemia potentially leading to new episodes of IE.

- Peripherally inserted intravenous lines are a safe alternative for prolonged antibiotic treatment but have a higher potential for mechanical problems, mainly obstruction.

- Beware of other catheters used in the setting of IE, mainly femoral haemodialysis catheters, as they are associated with the highest rates of line associated bacteraemia.

Strengths and limitations of this study

- The strength of the study is bringing practical information to those treating IE or other infections that require 4 or more weeks of intravenous therapy. Another strength is that catheters were compared by days of use, and Kaplan-Meier curves of CVC and PICC 'survival' were constructed for illustrating AEs.

- Limitations are that the study is a single-center one and was done over 1 year, a relatively short period of time.

defined as complications resulting from patient care which are not related to the underlying disease. They may result in sequelae, prolonging hospital stay or even resulting in death. ${ }^{12}$

$\mathrm{AE}$ resulting from intravenous catheter use may occur from the time of insertion, and 
may lead to premature removal of the device. These $\mathrm{AE}$ may cause local complications, which may be infectious or non-infectious or systemic complications, of which bloodstream infection is the most severe. ${ }^{3}{ }^{4}$ The literature shows that more than half the cases of nosocomial bacteraemia or candidaemia occurring between 1965 and 1991 resulted from vascular lines. ${ }^{56}$

Regarding the treatment of endocarditis, intravenous antibiotics are necessary for most patients for the time span of 4-6 weeks. Therefore, patients with infective endocarditis (IE) spend a long time in hospital and are vulnerable to acquisition of hospital infections, the most unwanted of all, bacteraemia with subsequent seeding of heart valves and a new episode of IE.

Therefore, acknowledging that IE is a severe infection that requires a prolonged intravenous antibiotic therapy, and that catheter-related bloodstream infection is an $\mathrm{AE}$ of major importance for its high morbidity and mortality, and that no studies in this group of patients have yet been published, the aim of the present study was to characterise the use of intravenous lines and the $\mathrm{AE}$ resulting from them in patients with IE admitted to a cardiac surgery referral hospital.

\section{METHODS}

This is an observational, analytical and prospective study on AEs resulting from the use of intravenous access sites in patients under antimicrobial treatment of IE. All patients admitted to Instituto Nacional de Cardiologia (INC), a tertiary care hospital for cardiac surgery in Rio de Janeiro, Brazil, between July 2009 and August 2010 were consecutively and prospectively enrolled after signing an informed consent form. Only possible or definite cases of IE, according to the modified Duke criteria, were included. ${ }^{7}$

Inclusion criteria were: being over 14 years of age, being admitted for the treatment of IE and signing the informed consent forms for participating in the International Collaboration on Endocarditis (ICE) study. Exclusion criteria were: patients admitted to the INC from another institution with intravenous therapy already completed or in use of intramuscular antibiotic therapy, catheters that were arterial or pulmonary artery catheters; patients who were admitted due to judicial mandates; patients who refused to sign the informed consent (or where this has been refused by the person in charge of the patients less than 18 years of age). The sample studied consisted of all episodes of IE in patients admitted in the study time period. IE was diagnosed by the modified Duke criteria. ${ }^{8}$ Patients may have had more than one episode of IE. Nosocomial IE was defined as that diagnosed $>72 \mathrm{~h}$ after hospital admission and there was no evidence that IE was present at the time of admission. ${ }^{9}$ Diagnoses made within 60 days of a previous hospital admission was also classified as nosocomial, or when a risk procedure for bacteraemia was performed. ${ }^{9}$ Cases of early prosthetic valve endocarditis, occurring within the first year of implantation, as well as IE related to pacemakers were included as nosocomial. Definition of a different episode of IE was when new clinical symptoms and signs of IE developed, or when new echocardiographic features presented or when isolation of a different microorganism from blood was made.

All intravenous lines were monitored from the time of IE diagnosis and start of intravenous antibiotic treatment till the end of treatment and device removal. Dialysis catheters used for the purpose of renal replacement were also monitored.

Types of lines were peripheral catheters (Introcan Safety, Melsungen, Germany), short-term central venous catheters (Arrow, Reading, Pennsylvania, USA), including haemodialysis (HD) catheters (Biomedical, São Paulo, SP, Brasil) and peripherally inserted central catheters_PICC (BARD, Murray Hill, New Jersey, USA). Infectious AEs_septic thrombophlebitis, bacteraemia, fungemia, endocarditis and metatastatic infections such as septic arthritis and osteomyelitis resulting from haematogenic spread from the colonised catheter ${ }^{3410}$ and non-infectious AE_infiltration, extravasation, accidental extrusion of the device, obstruction ${ }^{3410}$ were monitored for all catheters.

In INC, catheter care is as follows: peripheral catheters are inserted by staff nurses, using $70 \%$ alcohol solutions, and are changed every 4 days or less. Transparent dressings are used. Central venous catheters are inserted by physicians, and the catheter bundle is applied. ${ }^{11}$ Dialysis catheters are inserted by the renal team physicians. They are exclusively used for renal replacement therapy and are double lumen. No semi-implanted dialysis catheters were used in the study patients, as it is not a routine at INC. Most HD catheters are inserted in the femoral and jugular positions.

PICC catheter insertion is recommended whenever intravenous therapy duration is anticipated to last longer than 6 days. PICCs are placed by trained nurses who constitute a PICC team. Doctors have to request PICCs in order for them to be inserted.

The study was approved by the Ethics Committee in INC under number 230/2009.Continuous variables were expressed as mean, SD and median. Categorical variables were described as percentages. The association of categorical variables was studied with the $\chi^{2}$ test or Fisher's exact test when applicable. Survival analysis was done using Kaplan-Meier curves and differences were calculated using the log-rank test with the $\mathrm{R}$ statistical programme. All results were considered significant for a $\mathrm{p}$ value $<0.05$.

\section{RESULTS}

\section{Clinical and demographic data on IE episodes}

There were 37 episodes of IE in 35 patients in the study period. Of the 37 episodes, $38 \%$ were referred from other hospitals. Three $(8 \%)$ of the cases were possible IE and $92 \%$ cases definite by the modified Duke criteria. $^{8}$ 
Episodes of IE submitted to surgery (valve replacement or repair, and/or pacemaker or implantable defibrillator insertion) corresponded to $76 \%$ of cases. Of the 37 episodes, $54 \%$ were community-acquired and $46 \%$ were nosocomial. Of the 17 nosocomial cases, $35 \%$ were IE acquired in other hospitals and $11(65 \%)$ at our institution (tables 1 and 2).

Regarding predisposing cardiac conditions for IE, 21\% had previous IE, 14 (38\%) had rheumatic valvulopathy, $36 \%$ had prosthesis (mechanical prosthesis- $14 \%$ and bioprosthesis-22\%) and 3\% had congenital heart disease. None of the patients were intravenous drug users.

Median time of hospitalisation was 49 days.

As to antibiotics used in the treatment of these $37 \mathrm{epi}-$ sodes of IE, $26(70 \%)$ used gentamicin, $21(57 \%)$ of patients used vancomycin, 18 (49\%) ampicillin, $11(30 \%)$ rifampin, $10(27 \%)$ oxacillin, $9(23 \%)$ meropenem, 5 (14\%) cefepime, 5 (14\%) daptomycin and $4(11 \%)$ linezolid. The most frequently used combination of antibiotics were: (1) oxacillin, ampicillin and gentamicin, (2) ceftriaxone and oxacillin and (3) vancomycin, gentamicin and rifampin.

\section{Characterisation of intravenous catheters used in treatment}

Total number of intravenous catheters used was 253; $59 \%$ were peripheral, $34 \%$ were $\mathrm{CVC}$ and $8 \%$ were PICC. Of the 85 CVC, 21 (25\%) were HD catheters. All

\begin{tabular}{|c|c|}
\hline Variables & n (\%) \\
\hline Age & $44.32 \pm 15.32^{\star}$ \\
\hline \multicolumn{2}{|l|}{ Gender } \\
\hline Male & $23(63)$ \\
\hline Female & $14(37)$ \\
\hline \multicolumn{2}{|l|}{ Comorbidities } \\
\hline Arterial hypertension & $14(38)$ \\
\hline Diabetes mellitus & $5(14)$ \\
\hline Neoplasia & $3(8)$ \\
\hline \multicolumn{2}{|l|}{ Predisposition } \\
\hline Rheumatic valvulopathy & $14(38)$ \\
\hline Previous history of IE & $10(21)$ \\
\hline Bioprosthetic valves & $8(22)$ \\
\hline Mechanical valves & $5(14)$ \\
\hline \multicolumn{2}{|l|}{ Clinical features } \\
\hline Fever & $31(84)$ \\
\hline Vegetation on TEE $†$ & $30 / 37(81)$ \\
\hline New valvular regurgitation & $10(27)$ \\
\hline \multicolumn{2}{|c|}{ Affected valves (vegetations detected by TEE) } \\
\hline Aortic & $13(35)$ \\
\hline Mitral & $12(32)$ \\
\hline Tricuspid & $3(8)$ \\
\hline
\end{tabular}

\begin{tabular}{lc} 
Table 2 Distribution of microorganisms isolated in \\
patients with IE, INC, 2009-2010 \\
\hline Microorganisms & $\mathbf{n}(\%)$ \\
\hline Gram positives & 22 \\
'Viridans' streptococci & $8(21.6)$ \\
Abiotropia defective & $1(2.7)$ \\
Staphylococcus aureus & $3(8.1)$ \\
Staphylococcus epidermidis & $3(8.1)$ \\
Staphylococcus capitis & $1(2.7)$ \\
Enterococcus faecalis & $4(10.8)$ \\
Enterococcus sp & $2(5.4)$ \\
Gram negatives & 2 \\
HACEK & $1(2.7)$ \\
Serratia marcescens & $1(2.7)$ \\
Fungi & 5 \\
Candida parapsilosis & $2(5.4)$ \\
Candida tropicalis & $2(5.4)$ \\
Non-identified yeast & $1(2.7)$ \\
Blood cultures not taken & $2(5.4)$ \\
Negative blood cultures & $6(16.2)$ \\
Total number of episodes of IE & 37 \\
\hline IE, infective endocarditis; INC, Instituto Nacional de Cardiologia.
\end{tabular}

HD catheters were used for dialysis only, and all were double lumen, non-implantable devices.

Total number of peripheral catheter-days was 360 . When duration of devices was analysed, peripheral catheters remained in situ for $24 \mathrm{~h}$ in $22 \%$ of cases, for 24 to $48 \mathrm{~h}$ in $26 \%$, for 48 to $72 \mathrm{~h}$ in $40 \%$ and for 72 $96 \mathrm{~h}$ in $11 \%$. Only one peripheral catheter remained for longer than $96 \mathrm{~h}$. As to the location of peripheral intravenous access sites, $57 \%$ were inserted in the right arm and $41 \%$ in the left arm.

Total number of catheter-days for the 85 short-term intravenous catheters was 1156, with an average duration for each catheter of 14 days. The catheter that remained in situ the longest (55 days) was a haemodialysis catheter and no AEs were reported for it. Total number of catheter-days for the 21 haemodialysis catheters was 301, with an average of 14 days. Short-term central catheters were inserted in the internal jugular vein in $44 \%$ of cases, in the subclavian vein in $33 \%$ and in the femoral veins in $23 \%$. When analysing the haemodialysis catheters, $57 \%$ were inserted in the femoral vein and $43 \%$ in the jugular. None of the patients had previous renal replacement therapy therefore all dialysis catheters inserted were due to acute renal failure resulting from complications of IE.

Total number of catheter-days for the 20 PICC was 420. PICC remained in situ for an average of 21 days, and the one that stayed longest remained 44 days, being removed due to end of treatment. As to the site of insertion, $65 \%$ were in the right forearm (cephalic, basilic or median veins) and $35 \%$ in the left forearm.

Only three patients of $35(8.6 \%)$ used only one catheter type (CVC) along the full treatment course. Peripheral and central catheters were used in $14 / 35$ 
Table 3 Characteristics of the adverse events related to 253 intravenous catheters in the treatment of infective endocarditis, INC, 2009-2010

\begin{tabular}{|c|c|c|c|c|c|}
\hline AEs & $\begin{array}{l}\text { Peripheral catheter } \\
(n=148)\end{array}$ & $\begin{array}{l}\text { Central venous catheter } \\
(n=64)\end{array}$ & $\begin{array}{l}\text { Dialysis catheter } \\
(n=21)\end{array}$ & $\begin{array}{l}\text { PICC } \\
(n=20)\end{array}$ & p Value \\
\hline Erythema & 23 & 08 & 0 & 03 & 0.36806 \\
\hline Fever & 0 & 15 & 08 & 0 & 0.00001 \\
\hline Bacteraemia & 0 & 05 & 03 & 0 & 0.00854 \\
\hline $\begin{array}{l}\text { Unwanted } \\
\text { extrusion }\end{array}$ & 10 & 05 & 0 & 06 & 0.02490 \\
\hline Obstruction & 09 & 02 & 0 & 08 & 0.00001 \\
\hline
\end{tabular}

$\mathrm{AE}$, adverse event; INC, Instituto Nacional de Cardiologia; PICC, peripherally inserted central catheter.

$(40 \%) ; 5(14.3 \%)$ patients used three types of catheter (peripheral, CVC and PICG). This means $63 \%$ of patients used three or less types of catheter during treatment for IE.

\section{AEs related to intravenous access sites}

The most frequent AE related to peripheral catheters was erythema at the insertion site in 23/148 (16\%); soft tissue infiltration in $15(10 \%)$, unwanted extrusion in $10(7 \%)$; obstruction in 9 (6\%); pain and hardening of the insertion site in $7(5 \%)$ each. Fever was the most frequently observed AE for the CVCs (15/85, 18\%). Erythema at the insertion site was seen in $8(9 \%)$, unwanted extrusion in $5(8 \%)$; bacteraemia in 5 $(6 \%)$; leukocytosis and purulent discharge at the insertion site was seen in $3(3.5 \%)$ each; obstruction and serous exudate in 2 ( $2 \%$ ) each; allergy to the transparent dressing in $1(1 \%)$. Some of these results are presented in table 3 .

As to the observed AE in PICC, the most frequent was obstruction, seen in 8/20 (40\%) of cases; this was followed by partial exteriorisation of the device in $4(20 \%)$; a hardened vein was palpable in $3(15 \%)$ of cases, as was erythema; hardening of the insertion site was found in $2(10 \%)$; oedema, allergy to the transparent dressing and total accidental extrusion of the device were seen in $1(5 \%)$ of cases each.
Data regarding the six episodes of bacteraemia for all catheter types in the study are presented in table 4 . Two of the episodes of bacteraemia resulted in new IE, characterised by new echocardiographic findings and persistence of fever despite catheter removal. There was one bacteraemia for 400 PICC days, and five bacteraemias for 1156 central venous catheter days, with an infection rate of 2.4/1000 PICC-day and 4.3/1000 short-term central catheter-days. If HD catheters were analysed separately, infection rate would be 10/1000 HD catheterdays and 2.3/1000 short-term non-HD catheter-days. In absolute numbers, there were two bacteraemias for 62 short-term non-HD catheters, versus three bacteraemias for $21 \mathrm{HD}$ catheters $(3.2 \%$ vs $17 \%$ bacteraemias, not statistically significant).

\section{Analysis of AEs in relation to duration of devices in} device-days by Kaplan-Meier curves

In figure 1 the survival curves of short-term central venous catheters, (shortened as CIP) and of PICC (shortened as CIPP) are shown. Vertical lines along the horizontal survival lines represent each episode of an $\mathrm{AE}$, as obstruction in the first Kaplan-Meier curve, and as bacteraemia in the second. Statistical significance was found for obstruction $(\mathrm{p}<0.001)$ which was more common in PICC.

Table 4 Characteristics of the bacteraemia episodes related to intravenous catheters in the treatment of infective endocarditis, INC, 2009-2010

\begin{tabular}{|c|c|c|c|c|c|c|}
\hline Catheter type & $\begin{array}{l}\text { Catheter } \\
\text { duration }\end{array}$ & Insertion site & $\begin{array}{l}\text { Clinical } \\
\text { features }\end{array}$ & Microorganisms & $\begin{array}{l}\text { New episode } \\
\text { of IE }\end{array}$ & Outcome \\
\hline PICC & 31 & Basilic right arm & Fever & Enterococcus faecalis & Yes & $\begin{array}{l}\text { Discharged } \\
\text { home }\end{array}$ \\
\hline HD & 31 & Right femoral & Fever & Enterococcus faecalis & No & $\begin{array}{l}\text { Discharged } \\
\text { home }\end{array}$ \\
\hline HD & 9 & Right jugular & Fever & Candida tropicalis & Yes & Death \\
\hline HD & 13 & Right femoral & Fever & Klebsiella pneumoniae & No & $\begin{array}{l}\text { Discharged } \\
\text { home }\end{array}$ \\
\hline $\begin{array}{l}\text { Short-term } \\
\text { non-HD }\end{array}$ & 8 & Right subclavian & Fever & $\begin{array}{l}\text { Non-specified } \\
\text { Gram-negative rod }\end{array}$ & No & $\begin{array}{l}\text { Discharged } \\
\text { home }\end{array}$ \\
\hline $\begin{array}{l}\text { Short-term } \\
\text { non-HD }\end{array}$ & 42 & Right jugular & Chills & $\begin{array}{l}\text { Non-specified } \\
\text { Gram-negative rod }\end{array}$ & No & $\begin{array}{l}\text { Discharged } \\
\text { home }\end{array}$ \\
\hline
\end{tabular}


Obstruction events in central venous cathetes (CIP*) and in PICC (CCIP**)

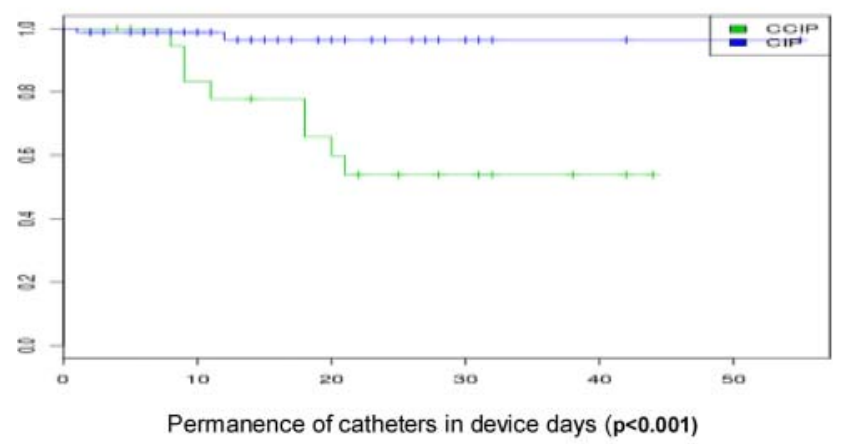

Bacteremia episodes in short term central venous catheters (CIP*) and in PICC ( CCIP**)

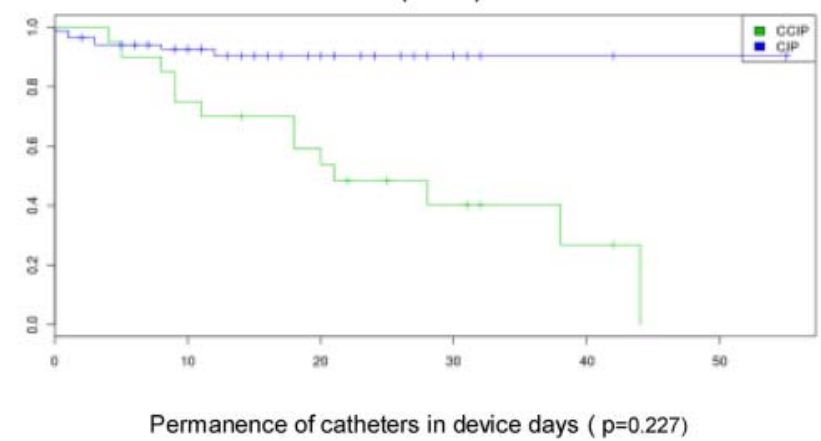

*CIP-short term central venous catheter (CVC)

**CCIP- Peripherally Inserted Central Catheter

Figure 1 Survival curves for short-term central venous catheters and for peripherally inserted central catheter with the adverse events bacteraemia and obstruction for catheters in the treatment of infective endocarditis, Instituto Nacional de Cardiologia, 2009-2010.

\section{DISCUSSION}

IE remains a condition of important morbidity and lethality, despite new surgical techniques. ${ }^{7}$ Antibiotics used in its treatment involves 'old' drugs, such as aqueous penicillin, intravenous ampicillin and vancomycin, for a time period of 4-6 weeks, all related to vein toxicity and potential phlebitis. ${ }^{7} 12$

It is well recognised that acid or basic drugs may cause lesion to the vascular endothelium. Therefore, medications with $\mathrm{pH}$ less than 5 or above 9 are likely to cause phlebitis, infiltration or extravasation, what reinforces the need for deep-intravenous access when they are used. In the treatment of IE, vancomycin has a $\mathrm{pH}$ of 2.4, ampicillin of 8-10, gentamicin 3.5-5 and oxacillin 6-8.5. ${ }^{13} 14$

These were drugs frequently used in our patients and their characteristics may partially explain some of the AEs described. Therefore, the need for deep-intravenous access is well recognised in IE treatment, as are the potential risks related to the use of these lines. ${ }^{9} 1415$

There are around 200000 nosocomial bloodstream infections yearly in the USA and many are related to the different intravenous catheters used in hospital practice. ${ }^{16}$
In a systematic revision, the incidence of infections related to peripheral catheters was 0.5 cases per catheter-day, 2.7 cases for central venous catheters and 2.1 for PICG in different departments (Intensive Care Unit, Surgery/Trauma Units, Haematology/Oncology, Haemodialysis, Clinical Care and Total Parenteral Nutrition) within different types of hospitals. ${ }^{5}$

In our study, there were no episodes of bacteraemia related to peripheral catheters, rate was $4.3 / 1000$ CVC-days (it was 10/1000 HD catheter-days) and 2.4/ 1000 PICC-days.

These numbers are not perfectly comparable, as our sample relates particularly to patients on intravenous antibiotics for IE. However, the numbers provide an estimate that suggest catheter care in our institution is similar to the literature. When analysing HD catheters, we concluded that bacteraemia rates are above the data shown in the literature. ${ }^{16}{ }^{20}$ This is probably due to the lack of use of semi-implantable HD catheters in our institution, and the use of the femoral route.

All patients in this study, which was done over a one-year period, had haemodialysis catheters inserted due to acute renal failure. We probably have a referral bias here, plus the study on catheters was done over a relatively short period of time. We often receive patients at our cardiac referral hospital to have their valves removed, mostly because of very severe valvular dysfunction. They have been referred from other hospitals, where heart failure and previous use of nephrotoxic drugs have induced acute renal failure. They are sick patients and get operated on urgently or emergently. On the other hand, those on chronic dialysis who acquire endocarditis are often too sick to be treated surgically and have a higher chance of not getting referred to us. Over the years of the ICE prospective study, we had a few patients with chronic renal failure and IE who were referred for surgery, but not in this study period.

Most of our patients used peripheral, short-term central venous catheters and/or PICC. The turnover of catheters was high, and to make results comparable, we have worked on catheter days, by catheter type, so that we can potentially generalise results. No published work on catheters used for antimicrobial therapy in patients with IE has been found in the literature, so that we cannot compare our experience with other centres. But we strongly suspect that most patients have peripheral catheters inserted before more definite venous access (CVC or PICG) is inserted, and certainly before haemodialysis catheters are inserted.

Bacteraemia is the most severe of AEs related to intravenous catheters. In cases of IE, bacteraemia may not only result in severe sepsis but also in seeding of diseased valves or valve prosthesis, and new episodes of IE. ${ }^{9}{ }^{15}$ This was seen in two of the patients in this series, (1) a 27-year-old woman, who had a new episode of IE caused by aminoglycoside resistant enterococcus but did well on clinical treatment and (2) a 33-year-old male patient who was a candidate for a heart transplantation due to intractable 
myocarditis of recent onset; he developed Candida tropicalis IE, due to the prolonged use of biventricular assist-device; he died of sepsis and coagulopathy.

When analysed separately, the peripheral catheters presented most often phlebitis, the short-term deep catheters fever and bacteraemia and PICC presented problems with manipulation, mainly obstruction and extrusion.

The use of the different catheter types follows clinical judgement. Most patients have a peripheral catheter inserted when they are admitted, for treatment of cardiac failure in most cases. When diagnosis of IE is established, recommendation is PICC insertion by INC hospital guidelines, but often this is only done following several days of admission. The main reasons for this are (1) lack of knowledge of hospital recommendations by residents; (2) insertion, at the operation room, of CVCs by anaesthesiologists and (3) late request for PICC insertion by the physicians, resulting in difficulty of insertion due to peripheral vein extensive use, phlebitis and sclerosis.

CVCs are preferred for the administration of fluids or vasoactive agents in the postoperative unit, and therefore PICCs are often inserted only after ICU discharge. This explains the variety of intravenous access used in our clinical practice.

According to these results, several of the AEs could be prevented if educational measures were implemented. First, use of the established protocols regarding catheter care would prevent overuse of peripheral catheters in IE and would promote the early insertion of PICC. Also, adequate handling of central venous catheters would avoid infection (CVCs and PICCs) and obstruction (PICCs) and early loss of the devices would be possible.

Although our study represents a small sample, it suggests that PICC was associated with less infective complications than CVC, as is described in the literature.

However, the manipulation of the PICG presented several other problems, such as loss of these devices due to 'obstruction' and 'extrusion'. These data need be expanded and a more thorough analysis made, so that a strong recommendation for the use of PICC as a first choice in the treatment of IE can be made.

A cost analysis would also be important in this decision (PICC vs CVC). Further studies need also to be done regarding the use of haemodialysis catheters in patients with IE, and it seems important to use semi-implantable catheters in this setting, and to avoid the femoral veins.

Although our study clearly shows a quantity and variety of AEs, with increase in morbidity, it could not show a higher mortality rate. However, it has the limitation of sample size and considers only same episode hospital discharge.

Acknowledgements We acknowledge all doctors and nurses involved in the care of the patients in this study.

Contributors DHGP, BRT and CCL participated in the conception and design of this study. DHGP participated in the acquisition of data. BRT participated in the analysis and interpretation of data with significant contribution to analysis by DHGP and CCL. All three authors participated in the drafting and approval of the final approval of the manuscript.
Funding None.

Competing interests None.

Patient consent Obtained.

Ethics approval Ethical approval was obtained from the Ethics Committee from Instituto Nacional de Cardiologia under number 230/2009.

Data sharing statement 'Extra data can be accessed via the Dryad data repository at http://datadryad.org/ with the doi:10.5061/dryad.kp064'.

\section{REFERENCES}

1. Gallotti RMD. Eventos adversos e óbitos hospitalares em serviço de emergências clínicas de um hospital universitário terciário: um olhar para a qualidade da atenção (tese de doutorado). São Paulo: Faculdade de Medicina da Universidade de São Paulo, 2003.

2. Baker GR, Norton PG, Flintoft V, et al. The Canadian Adverse Events Study: the incidence of adverse events among hospital patients in Canada. JAMC 2004;170:1678-86.

3. Beghetto $\mathrm{M}$, Victorino J, Teixeira $\mathrm{L}$, et al. Fatores de risco para infecção relacionada a cateter venoso central. Revista Brasileira Terapia Intensiva 2002;14:107-13.

4. Pereira RCC, Zanetti ML. Complicações decorrentes da terapia intravenosa em pacientes cirúrgicos. Rev. Latino-am. Enfermagem 2000;8:21-7. http www.scielo.br/pdf/rlae/v8n5/12363.pdf (accessed 4 Aug 2010).

5. Maki DG, Kluger DM, Christopher J. The risk of bloodstream infection in adults with different intravascular devices: a systematic review of 200 published prospective studies. Mayo Clin Proc 2006;81:1159-71.

6. Lamas CC, Eykyn SJ. Hospital acquired native valve endocarditis: analysis of 22 cases presenting over 11 years. Heart 1998;79:442-7.

7. Habib G, Hoen B, Tornos P, et al. Guidelines on the prevention, diagnosis, and treatment of infective endocarditis (new version 2009). Euro Heart J 2009;30:2369-413.

8. Li JS, Sexton DJ, Mick N, et al. Proposed modifications to the Duke criteria for the diagnosis of infective endocarditis. Clin Infect Dis 2000;30:633-8.

9. Martín-Dávila P, Fortún J, Navas E, et al. Nosocomial endocarditis in a tertiary hospital. Chest 2005;128:772-9.

10. Lanbek P, Odenholt I, Paulsen O. Antibiotics differ in their tendency to cause infusion phlebitis: a prospective observational study. Scand $J$ Infect Dis 2002;34:512-19.

11. Provonost $P$, Needham $D$, Berenholtz $S$, et al. An intervention to decrease catheter-related bloodstream infections in the ICU. New Engl J Med 2006;355:2725-32.

12. Baddour LM, Wilson WR, Bayer AS, et al. Infective endocarditis: diagnosis, antimicrobial therapy and management of complications. Circulation: a statement for healthcare professionals from the Committee on Rheumatic Fever, Endocarditis, and Kawasaki Disease, Councilon Cardiovascular Disease in the Young, and the Councils on Clinical Cardiology, Stroke, and Cardiovascular Surgery and Anesthesia, American Heart Association: Endorsed by the Infectious Diseases Society of America. Circulation 2005;111:e394-434.

13. Earhart A. Diagnostic tools and therapeutic interventions that may influence the integrity of vascular and nonvascular access devices. $J$ Infusion Nurs 2005;28:S13-17.

14. Roszell S, Jones C. Intravenous administration issues. J Infusion Nurs 2010;33:112-18.

15. Fernandes AT, Furtado JJD, Porfírio FMV, et al. Infecção hospitalar da corrente sanguínea. (Hospital acquired blood stream infection). In: Fernandes AT, ed. Infecção hospitalar e suas interfaces na área da saúde. São Paulo: Ed. São Paulo, 2000:580-606.

16. Centers for Disease Control and Prevention. Guidelines for the prevention of intravascular catheter-related infections. MMWR 2002:51(RR-10):1-32.

17. Mermel LA, Farr BM, Sherertz RJ, et al. Guidelines for the management of intravascular catheter-related infections. $J$ Intravenous Nurs 2001;24:180-205.

18. Johnston BL, Conly JM. Central venous catheter-associated bloodstream infections in hemodialysis patients: another patient safety bundle? Can J Infect Dis Med Microbiol 2006;17:99-102.

19. Kamalakannan D, Pai RM, Johnson LB, et al. Epidemiology and clinical outcomes of infective endocarditis in haemodyalisis patients. Ann Thorac Surg 2001;83:2081-6.

20. Nucifora G, Badano LP, Viale $P$, et al. Infective endocarditis in chronic haemodyalisis patients: an increasing clinical challenge. Euro Heart J 2007;28:2307-12. 